\title{
VALIDADE E CONFIABILIDADE DO MÉTODO DE CUSTO DE VIAGEM: UM ESTUDO APLICADO AO PARQUE NACIONAL DA SERRA GERAL
}

\author{
A. Gori Maia ${ }^{\S}$ \\ Ademar R. Romeiro ${ }^{\text {a }}$
}

\begin{abstract}
RESUMO
O objetivo principal deste trabalho é analisar a validade e a confiabilidade da valoração econômica obtida pela aplicação do método de custo de viagem ao Parque Nacional da Serra Geral. A revisão dos pressupostos teóricos da metodologia e das principais recomendações da literatura permitiu analisar a validade de conteúdo da estimativa e, para verificar sua confiabilidade, simulou-se o efeito de possíveis variações da amostra sobre o resultado final da valoração.
\end{abstract}

Palavras-chave: método de custo de viagem, valoração econômica, excedente do consumidor.

\begin{abstract}
The main purpose of this paper is to analyze the validity and reliability of an economic valuation obtained by travel costs method applied to Serra Geral National Park (Brazil). The review of the theoretical postulates of methodology and of the main literature recommendations adds arguments to analyze the content validity of the estimation and, in order to analyze its reliability, it was simulated the effect of possible sample variations on the final result of valuation.
\end{abstract}

Keywords: travel costs method; economic valuation; consumer surplus.

JEL classification: Q51, Q26, Q21.

$\S \quad$ Pesquisador do Instituto de Economia da Universidade Estadual de Campinas (UNICAMP) - Núcleo de Economia Agrícola e do Meio Ambiente (NEA). E-mail: gori@eco.unicamp.br.

a Professor do Instituto de Economia da Universidade Estadual de Campinas (UNICAMP) e Pesquisador do Núcleo de Economia Agrícola e do Meio Ambiente (NEA). E-mail: ademar@eco.unicamp.br.

Endereço para contato: Universidade Estadual de Campinas - Cidade Universitária “Zeferino Vaz” - Distrito de Barão Geraldo - Caixa Postal 6135 - Campinas / SP - CEP: 13083-857.

Recebido em novembro de 2006. Aceito para publicação em março de 2008. 


\section{INTRODUÇÃo}

Uma das discussões correntes desde a Conferência sobre Meio Ambiente e Desenvolvimento das Nações Unidas (UNCED), realizada em 1992 no Rio de Janeiro, é sobre a mensuração do desenvolvimento sustentável, um conceito normativo que afirma ser possível conciliar crescimento econômico e uso sustentável dos recursos naturais. Até então, as estatísticas sobre o meio ambiente eram totalmente dissociadas da economia. Embora produzissem índices considerados úteis para organizar e apresentar dados ambientais em quantidades físicas, eram incapazes de incorporar dados monetários para permitir a conexão com variáveis econômicas (De Carlo, 2000)

A elaboração de estatísticas capazes de fornecer informações mais evidentes sobre a relação entre desenvolvimento econômico e o uso ou estágio de degradação do meio ambiente é uma das condições necessárias para se avaliar a sustentabilidade de um dado processo de desenvolvimento. É uma maneira de descrever a interação entre as atividades humanas e o meio ambiente, fornecendo referências essenciais para projetos e programas de avaliação ambiental (Pearce, 1993). Mais ainda, é uma das condições necessárias para o processo de conscientização ecológica, sem o qual não é politicamente viável implementar as políticas ambientais necessárias para garantir a sustentabilidade no longo prazo (Romeiro, 2004).

A literatura sugere uma série de métodos de valoração capazes de fazer essa conexão entre o uso e provisão dos recursos naturais e a estimativa econômica de seus benefícios (Maia et al., 2004). Alguns procuram obter o valor do recurso diretamente a partir das preferências das pessoas, utilizando-se de mercados hipotéticos ou de bens complementares para obter a disposição a pagar (DAP) dos indivíduos, e podem ser classificados como métodos diretos. Por sua vez, os denominados métodos indiretos procuram obter o valor do recurso por meio de uma função de produção relacionando o impacto das alterações ambientais a produtos com preços no mercado.

Os métodos indiretos são mais simples e menos onerosos. Estimam o impacto de uma alteração ambiental na produção de bens e serviços comercializáveis, como a redução da qualidade do solo que afeta a produtividade agrícola e, conseqüentemente, os rendimentos de um produtor. Embora as estimativas indiretas sejam quase sempre subestimadas, pois captam apenas valores de uso dos recursos ambientais, muitas vezes são suficientes para viabilizar, por exemplo, o uso sustentável de um ambiente.

Entretanto, em muitas situações, a maior parte do valor de um recurso ambiental provém de valores de não uso, relacionados à ética, cultura, religião, ou simples preservação de hábitats naturais. Nestas circunstâncias, os métodos diretos são os únicos capazes de captar estes tipos de valores por meio da DAP da população pelo bem ou serviço ambiental.

Ainda não há um consenso quanto à eficiência de um método em relação ao outro, mesmo porque não há como precisar o real preço de um bem ou serviço ambiental. Temos ainda um profundo desconhecimento das complexas relações da biodiversidade, da capacidade de regeneração do ambiente e seu limite de suporte das atividades humanas. Um processo que resume toda a complexidade ambiental numa simples medida de valor monetário irá indubitavelmente provocar uma importante perda de informação (Bromley, 1995). Cada método apresenta uma eficiência específica para deter- 
minado caso, mas a maior dificuldade de todos se encontra na estimativa de valores relacionados à própria existência do recurso ambiental, sem considerar sua utilidade atual ou futura. ${ }^{1}$

Entretanto, apesar destas limitações, ${ }^{2}$ a valoração monetária da degradação ambiental é fundamental para, num plano mais geral, o processo de tomada de decisão em relação à definição de prioridades de políticas de preservação ambiental e, num plano específico, como elemento imprescindível em processos judiciais de indenização por danos causados ao ambiente ou desapropriação de propriedades privadas para fins de preservação ambiental.

O uso freqüente da valoração em processos de indenizações judiciais exige, entretanto, estudos mais criteriosos sobre a validade e confiabilidade dessas estimativas econômicas, que correspondem, respectivamente, a medidas de exatidão e precisão estatística. A falta de um parâmetro consistente pode favorecer o comportamento oportunista e beneficiar pequenos e poderosos grupos de interesse.

Para verificar a validade e a confiabilidade da valoração econômica obtida pelo método de custo de viagem (MCV), este trabalho propõe-se a estudar o caso do Parque Nacional da Serra Geral em um recurso da justiça durante um processo de indenização aos proprietários desapropriados. A análise da metodologia e dos resultados da pesquisa permitiu avaliar a consistência da estimativa econômica, fornecendo importantes elementos para avaliar futuras aplicações da metodologia.

\section{O valor econômico do Parque Nacional da Serra Geral}

Localizado nos Estados de Santa Catarina e Rio Grande do Sul, o Parque Nacional da Serra Geral (PNSG) foi criado pelo IBAMA em 1992, ${ }^{3}$ como forma de expansão da área de proteção do já existente Parque Nacional dos Aparados da Serra (PNAS). A área de proteção atual totaliza 17.300 hectares e possui belezas cênicas raras, com inúmeros canyons, cachoeiras e espécies ameaçadas da fauna e flora.

A valoração econômica foi um recurso da justiça durante processo de desapropriação e indenização dos proprietários das terras. Dada as peculiaridades do objeto de estudo, o método de custo de viagem foi uma das propostas de avaliação econômica apresentada à justiça, que decidiria por aquela mais apropriada ao processo de indenização. Por ser um parque aberto à visitação pública, as estimativas do MCV permitiriam uma estimativa indireta da disposição a pagar dos visitantes, baseando-se em gastos efetivamente praticados por estes para visitar o patrimônio natural. O parque recebe diariamente inúmeros turistas de diversas partes do País e até do mundo, o que também facilitaria e reduziria os custos da aplicação e captação dos questionários da pesquisa, dando mais validez e confiança às estimativas.

1 Valores de existência estariam relacionados a questões morais, culturais, éticas ou altruística dos indivíduos em relação à existência dos bens ambientais

2 O grupo de trabalho do Professor Robert Constanza no Instituto GUND da Universidade de Vermont desenvolveu inicialmente com esta finalidade um meta-modelo global unificado da biosfera (GUMBO - Global Unified Meta-Model of Biosphere) e atualmente trabalha com uma nova modelagem de serviços ecossistêmicos, derivada deste, que procura integrar diferentes modelos em múltiplas escalas (MIMES - Multiscale Integrated Models of Ecosystem Services). Para maiores detalhes sobre o GUMBO, ver Boumans et al. (2002).

3 Decreto de lei n $^{\circ} 531$ de 20/05/1992. 
Como as áreas da região são utilizadas majoritariamente para a criação de gado, o custo de oportunidade da pecuária oferecia também uma estimativa fácil e direta do preço de mercado das propriedades, sendo outra proposta apresentada à justiça. Estes se baseavam na produtividae média da pecuária da região e equivalia a aproximadamente $1.000 \mathrm{Kg} / \mathrm{ha}$ ou $\mathrm{R} \$ 1.500 / \mathrm{ha}$ em 2004. A maior limitação do método do custo de oportunidade é que este tende a subestimar os diversos serviços ecossistêmicos que possam estar associados ao patrimônio natural, assim como os reais benefícios das amenidades ambientais à população. Isto porque a beleza cênica e a preservação das espécies animais e vegetais, principais atributos ambientais da região, não seriam contemplados nas estimativas que consideraram apenas valores associados à exploração econômica das áreas adequadas à pecuária.

Uma pesquisa direta de avaliação contingente, por sua vez, traria a vantagem de captar até mesmo os valores relacionados à existência da preservação do parque, mas esbarraria nas dificuldades inerentes à descrição dos complexos atributos ambientais presentes no PNSG. Esta complexidade ambiental dificultaria a implementação da pesquisa e poderia abrir margem à contestação dos resultados. Outra limitação do método de avaliação contingente é seu custo de implementação, que exige pesquisas melhor elaboradas e entrevistas fora do local de visitação para captar valores de não uso da população.

O ideal seria obter, por meio de modelagem ecossistêmica, uma visão clara de todos os serviços ecossistêmicos envolvidos no parque e, a partir daí, escolher a metodologia de valoração mais apropriada ao problema ambiental. Entretanto, limitações operacionais, custos e tempo de execução da pesquisa acabam freqüentemente influenciando a escolha da metodologia de análise.

A pertinência do MCV ao problema proposto e seus custos relativamente baixos de implementação corroboraram para sua escolha como uma das ferramentas de avaliação econômica do PNSG. Ao mesmo tempo em que se procurou considerar a maior amplitude de atributos ambientais do PNSG com o MCV, buscou-se associar estes valores a gastos efetivamente praticados pela população para dar mais credibilidade às estimativas. A finalidade da pesquisa exigiu ainda um estudo mais apurado sobre o conteúdo teórico da valoração, ou seja, verificar se a medida obtida refletia todas as dimensões analíticas do problema e atendia à proposta judicial da valoração. É o tipo de análise que a literatura costuma denominar de validade de conteúdo (Carmines e Zeller, 1979), a qual relaciona-se estritamente à abrangência temática da medida empírica. Nela, o conceito deve estar bem claro para que a análise possibilite verificar se todos os diferentes aspectos teóricos foram identificados.

Para validar o conteúdo das estimativas do MCV aplicado ao PNSG, este trabalho propôs-se a revisar os pressupostos teóricos da metodologia e as principais recomendações da literatura (Smith e Kaoru, 1990; Hanley e Spach, 1993), relacionando-os aos resultados da pesquisa. Será ainda realizado um estudo da confiabilidade das estimativas, simulando o efeito de possíveis variações amostrais sobre a estimativa econômica. Ao final, pretende-se reunir elementos para analisar a viabilidade do uso da estimativa econômica em um processo de indenização judicial.

Para cumprir tais objetivos, este trabalho foi estruturado em três módulos principais, além destas duas partes introdutórias: i) um breve resumo dos pressupostos teóricos do MCV; ii) resumo dos resultados da pesquisa aplicada ao PNSG, relacionando-os às principais recomendações da literatura; iii) análise dos resultados e considerações finais. 


\section{O MÉTODO DE CUSTO DE VIAGEM}

O custo de viagem é a mais antiga metodologia de valoração econômica, ${ }^{4}$ aplicada principalmente a patrimônios naturais de visitação pública. $\mathrm{O}$ método deriva os benefícios econômicos atribuídos pela população a um patrimônio natural a partir dos gastos efetivos dos visitantes para se deslocar até o local, o que inclui transporte, tempo de viagem, taxa de entrada, hospedagem, alimentação, entre outros gastos complementares.

As estimativas econômicas do MCV costumam referir-se apenas a valores de uso direto dos serviços prestados pelo patrimônio natural, ${ }^{5}$ já que somente as disposições a pagar dos visitantes são consideradas. Entretanto, uma estimativa mais abrangente poderia ser obtida considerando também propensos visitantes fora do local de visitação, que revelariam um valor de opção ${ }^{6}$ pelo patrimônio, mediante possíveis alterações na qualidade do serviço oferecido ou redução no custo de viagem.

A partir de uma função que relaciona a taxa de visitação ao custo de viagem, aplica-se a teoria econômica do excedente do consumidor para estimar a disposição adicional a pagar da população pelas visitas, uma estimativa dos benefícios econômicos líquidos proporcionados pelo patrimônio natural à população. $\mathrm{O}$ excedente do consumidor é uma medida do bem-estar da população, obtido a partir da diferença entre a disposição a pagar da população por um bem ou serviço e seu custo efetivo de apropriação. Pode ser facilmente calculado quando se conhece a função demanda pelo bem ou serviço que, no caso do MCV, relacionaria a variável dependente número de visitantes (taxa de visitação) à variável independente custo de viagem ao patrimônio natural.

Entretanto, além do próprio custo de viagem, variáveis como as características socioeconômicas dos visitantes e a proximidade a substitutos naturais podem também influenciar a demanda por visitação e devem ser consideradas como fatores de controle na função demanda pelo patrimônio natural. Todas estas informações costumam ser coletadas em entrevistas aplicadas no próprio local de visitação, o que acaba sendo um fator limitante das estimativas do MCV. Apenas os valores de uso direto do patrimônio natural são considerados, ou seja, supõe-se que apenas os visitantes possuam utilidades marginais positivas pelos bens ou serviços ambientais prestados pelo patrimônio.

Já a variável dependente demanda por visitas costuma ser representada de duas formas principais: i) freqüência de visitantes por grupo de habitantes de uma localidade (por exemplo, número de visitas anuais a cada grupo de mil habitantes); ii) freqüência individual de visitas num determinado horizonte de tempo (por exemplo, número anual de visitas de cada indivíduo). Embora não haja consenso sobre a forma mais apropriada, estudos constatam diferenças significativas entre as estimativas econômicas obtidas por cada uma das técnicas; ${ }^{7}$ o que não surpreende, uma vez que o comportamento individual subjacente a cada uma é distinto.

4 Segundo Hanley e Spash (1993), as primeiras publicações do método foram feitas em 1958 por Wood e Trice e em 1966 por Clawson e Knetsch. Entretanto, a primeira menção à técnica ocorreu já em 1947, em uma carta do economista Harold Hotelling ao diretor do Serviço Nacional de Parques norte-americano (US Park Service).

5 Valores de uso direto referem-se à apropriação direta dos recursos ambientais, via extração, visitação ou outra atividade de produção ou consumo direto. Para maiores detalhes, ver Maia, Romeiro e Reydon (2003).

6 Valores de opção referem-se à intenção de consumo do bem ou serviço ambiental no futuro.

7 Willis e Garrod (1989) mostram, por exemplo, que os valores recreacionais estimados para parques florestais na Grã-Bretanha foram significativamente inferiores quando utilizadas visitas individuais por ano, ao invés de visitas por grupo de habitantes. 
De maneira geral, a demanda por visitas, $V$, será uma função do custo de viagem, $C V$, controlando-se as características socioeconômicas dos visitantes, $S E$, e a existência de substitutos, $S B$, ao patrimônio natural, que pode ser, por exemplo, o custo de viagem do substituto natural mais próximo à região de procedência do visitante. Tem-se, então, a seguinte representação para a função demanda pelo patrimônio natural:

$$
V=f(C V, S E, S B)
$$

A partir da função (1) é possível inferir o impacto de um aumento no custo de viagem, $C V$, sobre a taxa de visitação ao patrimônio natural e, expandindo a estimativa à população total, simular o efeito de possíveis taxas de entrada sobre a demanda esperada. Mantendo-se constantes os fatores socioeconômicos, $S E$, e o custo de substitutos naturais, $S B$, ainda é possível estabelecer a relação inversa entre taxa de visitação, $V$, e custo de viagem, $C V$, ou seja, inferir a disposição a pagar da população, $C V$, em função da taxa de visitação, $V$. Esta relação inversa é definida pela expressão (2) e representada graficamente pela Figura 1.

\section{Figura 1 - Função demanda pelo patrimônio natural}

$$
C V=f(V)
$$

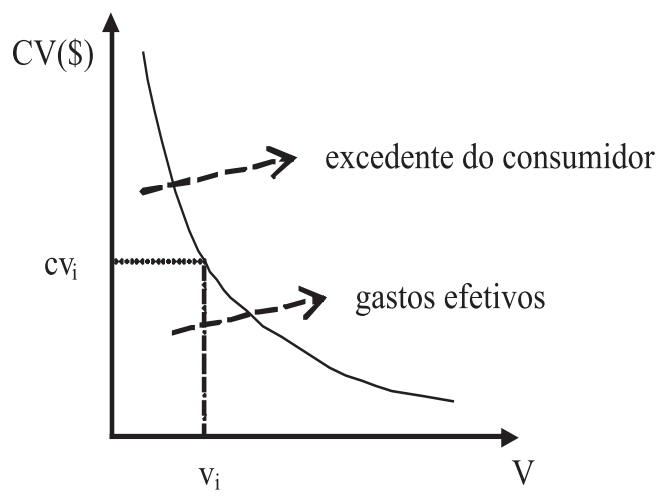

De acordo com a expressão (2), dada uma taxa de visitação, $v_{i}$, tem-se um determinado custo efetivo de viagem, $\mathrm{c} v_{i}$. Como demonstra a teoria econômica, a área abaixo da função $C V$ e acima dos gastos de viagem efetivamente praticados $\left(\mathrm{c} v_{i}\right)$ representa o excedente do consumidor, uma estimativa econômica do serviço ambiental prestado pelo patrimônio natural. Em outras palavras, trata-se de estimar o quanto, a mais do que foi efetivamente gasto, cada visitante - ou grupo de visitantes na hipótese de uma curva de demanda agregada - estaria disposto a pagar pelas visitas.

Este excedente $E C$ pode ser calculado pela expressão matemática:

$$
E C=\int_{0}^{v_{i}} f(V) d V-v_{i} c v_{i}
$$

Ou, dada a função demanda (1), o EC pode ainda ser diretamente estimado por: 


$$
E C=\int_{c v_{i}}^{+\infty} f(C V, S E, S B) d C V
$$

\section{O MÉTOdo DE CUSTO DE VIAGEM APLICAdO AO PNSG: RECOMENDAÇÕES DA LI- TERATURA E RESUMO DOS RESULTADOS}

Após um breve relato dos pressupostos teóricos do MCV, as principais recomendações da literatura serão relacionadas aos resultados obtidos para o PNSG. O objetivo é reunir argumentos para analisar a validade e confiabilidade das estimativas do MCV e discorrer sobre a credibilidade da valoração no processo de indenização judicial do PNSG.

A pesquisa baseou-se em 335 questionários aplicados aos visitantes durante os meses de abril a setembro de 2004. Não foi adotado nenhum critério especial de planejamento amostral, pois a aplicação dos questionários ficou sob a responsabilidade e disponibilidade dos funcionários do parque. Embora esse processo possa estar sujeito a um viés de seleção, este será considerado de probabilidade remota, pois os funcionários desconheciam as reais motivações da pesquisa e não teriam motivos para torná-la tendenciosa.

Pressupondo que a seleção obtida pelos funcionários do parque represente uma amostra aleatória simples, outra preocupação refere-se-se à confiabilidade da amostra e à representatividade do caráter sazonal das visitas. Caso sejam previstas, por exemplo, diferenças significativas no perfil dos visitantes nos diferentes meses do ano, é recomendável obter uma amostra representativa para cada um destes. Este procedimento acaba, entretanto, sujeito a limitações de tempo para finalização e orçamento disponível para realização da pesquisa, que nem sempre permite um período amplo de captação dos questionários. Diferenças no perfil dos visitantes durante os dias da semana também devem ser consideradas. No estudo do PNSG, constatou-se, por exemplo, que os visitantes de localidades mais distantes, com maiores custos de viagem, concentram suas visitas de segunda a sexta, enquanto nos finais de semana há relativamente mais visitantes de localidades mais próximas ao parque, com menores custos de viagem.

Embora o estudo do efeito sazonal da amostra durante os meses do ano esteja além das limitações desta pesquisa, que limitou suas entrevistas a seis meses do ano, foi possível avaliar a representatividade da amostra durante os dias da semana e sua confiabilidade no conjunto total. Como demonstra Cochran (1953), dada uma confiança $\alpha$, o erro de mensuração $e$ de uma amostra de tamanho $n$ de uma população finita de tamanho $N$ será dado por:

$$
e=Z_{\alpha} \frac{\sigma}{\sqrt{n}} \sqrt{\frac{N-n}{N-1}}
$$

onde $Z_{\alpha}$ é o valor da tabela normal padronizada equivalente a $\alpha$ de probabilidade e $\sigma$ o desvio padrão da variável em estudo. Como o valor de $\sigma$ é, a priori, desconhecido, costuma-se adotar uma estimativa conservadora assumindo o valor máximo de $\sigma$ para uma variável dicotômica $(0,5)$. Dados os valores de $N$ e $n$, foi possível simular o erro de estimação e a confiança das estimativas 
da amostra. ${ }^{8}$ Pressupondo, por exemplo, um erro de estimação de 5\%, a Tabela 1 apresenta estimativas da confiança da amostra para cada dia da semana e no seu conjunto total.

Tabela 1 - Confiança da amostra $(\alpha)$ para um erro de estimação de $5 \%$

\begin{tabular}{lcccc}
\hline Dia da Semana & $\begin{array}{c}\text { Visitantes Esperados } \\
\left(N_{e}\right)\end{array}$ & $n$ & $\alpha$ & $\begin{array}{c}\text { Fator Expansão } \\
\left(N_{e} / n\right)\end{array}$ \\
\hline Domingo & 8.175 & 70 & 0,60 & 117 \\
Segunda-feira & 6.337 & 58 & 0,56 & 109 \\
Terça-feira & 3.474 & 69 & 0,60 & 50 \\
Quarta-feira & 2.504 & 34 & 0,44 & 74 \\
Quinta-feira & 2.392 & 22 & 0,36 & 109 \\
Sexta-feira & 1.557 & 25 & 0,39 & 62 \\
Sábado & 4.632 & 57 & 0,55 & 81 \\
\hline Total & 29.071 & 335 & 0,93 & 87 \\
\hline
\end{tabular}

Fonte: Dados da pesquisa.

A ausência de amostragem proporcional foi responsável por diferenças significativas entre as confianças da amostra em cada dia da semana e exigiu a adoção de diferentes fatores de expansão da amostra. ${ }^{9}$ De maneira geral, pode-se afirmar que, embora a amostra não seja significativa para inferir valores para cada dia da semana, apresenta validez e confiança suficiente para analisar a população em seu conjunto total. Por exemplo, embora a confiança da amostra para as sextas-feiras seja de apenas $36 \%$, a amostra, em seu conjunto total, apresenta uma confiança de $93 \%$ para um erro de estimação de $5 \%$.

Além do planejamento amostral, o tratamento dos dados também cumpre papel essencial na confiabilidade dos resultados. Para avaliar as principais fases de tratamento dos dados e as limitações impostas pela pesquisa aplicada ao PNSG, as próximas análises serão apresentadas em seis módulos, associando-as a cada uma das principais recomendações da literatura. Todas as estimativas econômicas apresentadas referem-se a valores em reais de julho de 2004.

\subsection{Escolha da variável dependente}

A primeira questão em uma pesquisa de CV remete-se à escolha da variável dependente para representar a demanda por visitas ao patrimônio natural. Como apresentado anteriormente, essa pode ser representada pelo número de visitas individuais em um determinado horizonte de tempo (visitas/período), ou por uma estimativa agregada, dada pela proporção de habitantes de uma localidade que visita o patrimônio em um determinado horizonte de tempo (visitas/pop).

8 Foi possível estimar o número esperado de visitas em cada dia da semana a partir do histórico de informações disponibilizado pela direção do parque.

9 Por exemplo, foram aplicadas 58 entrevistas às segundas-feiras, e sendo de 6.337 o número estimado de visitantes neste dia da semana segundo o controle do parque, cada entrevistado na segunda-feira estaria representado 109 (6.337/58) pessoas na população. 
O modelo econométrico da primeira representação (visitas/período) relacionará os gastos individuais e outras características socioeconômicas dos visitantes à freqüência de visitação em um determinado horizonte de tempo, que pode, por exemplo, ser o número de visitas anuais (visitas/ ano). Essa forma funcional não é, entretanto, recomendada em situações como a do PNSG, onde há visitantes das mais distantes localidades, que limitam suas visitas a poucos dias no ano ou da vida, ${ }^{10}$ comprometendo a representatividade do modelo econométrico em virtude da baixa variabilidade do regressando.

Assim, como os gastos de viagem e demais características dos visitantes costumam também estar associados às respectivas regiões de procedência, é comum a representação pela demanda agregada de dado local de origem (visitas/pop). Nessa condição, o modelo econométrico relacionará os gastos médios e as características de cada região à respectiva proporção de visitantes de cada localidade, usualmente representada por visitas a cada grupo de mil habitantes (visitas/1000 hab). O principal problema desse tipo de representação é que desconsidera a heterogeneidade interna dos indivíduos no que se refere aos custos de viagem e oportunidade dos indivíduos (Ortiz et al., 2000).

Ciente da viabilidade analítica e das limitações de cada representação, adotou-se a representação agregada para a demanda, identificando 95 municípios como diferentes localidades de origem dos visitantes. ${ }^{11}$ As demandas foram expressas em número de visitas anuais para cada grupo de mil habitantes e obtidas a partir da ponderação entre o número anual esperado de visitas e a população estimada para o município de origem em $2004 .^{12}$

\subsection{Cálculo do custo de viagem}

O custo de viagem deve referir-se ao valor total das despesas que cada indivíduo abre mão para visitar o parque. Deve, portanto, considerar gastos relativos com o transporte para se chegar ao parque e regressar à cidade de origem, hospedagem e alimentação nos dias dedicados à visitação, além do próprio custo de oportunidade do visitante, uma estimativa do valor-hora de lazer da pessoa. ${ }^{13}$

Enquanto os gastos individuais com alimentação e hospedagem podem ser facilmente obtidos a partir de questionamentos aos visitantes, e assim foram no caso do PNSG, os custos do transporte costumam ser estimados indiretamente, já que os próprios entrevistados usualmente desconhecem os reais gastos envolvidos na viagem. Isto porque, quando se utiliza o automóvel como veículo de transporte, por exemplo, não somente os gastos diretos com combustível e pedágio devem ser contabilizados, mas também gastos indiretos de difícil projeção, como óleo do motor, pneus, manutenção, depreciação, seguro, entre outros.

10 Para se ter uma idéia, $85 \%$ dos visitantes do PNSG disseram estar visitando o parque pela primeira vez, e outros $10 \%$ declararam ser a $2^{\text {a }}$ visita em 5 anos.

11 Cinco localidades de origem estrangeira foram excluídas da análise por representarem valores demasiadamente extremos aos observados. Outras quatro foram reagrupadas - Goiânia e Formosa, Belo Horizonte e Viçosa - para corrigir distorções das estimativas e dar maior significância estatística ao modelo econométrico.

12 O número anual esperado de visitas para cada município foi obtido pela expansão dos visitantes entrevistados à população, e a população estimada do município obtida a partir de informações do Censo Demográfico 2000, ajustando-se os valores para 2004 segundo a taxa especifica de crescimento estimada pelo IBGE para cada Estado de origem.

13 A estimativa econômica do custo de oportunidade da pessoa será discutida com maiores detalhes na próxima seção. 
Como os gastos de transporte estão diretamente relacionados à distância percorrida e ao tempo de viagem, é comum adotar um veículo padrão de transporte para estimar os gastos médios de cada localidade. No caso do PNSG, por exemplo, optou-se pelo automóvel como veículo padrão, já que era o meio de transporte de $96 \%$ de seus freqüentadores.

A escolha do veículo de referência para cálculo dos custos de transporte cumpre papel essencial na análise, já que esses gastos costumam representar parcela significativa dos custos totais de viagem. ${ }^{14}$ Para obter resultados confiáveis e evitar uma possível superavaliação do custo total, sugere-se a adoção de uma estimativa conservadora, ou seja, um custo de transporte padrão que seja coerente com os gastos efetivamente praticados e que minimize qualquer possibilidade de superestimação dos valores.

Para obter uma estimativa com credibilidade em um processo judicial, esse trabalho optou por uma norma oficial do Tribunal de Contas do Estado de Pernambuco (Resolução TC N 06/93), que estabelece o valor $\mathrm{R} \$ 0,66$ como forma de cálculo monetário dos gastos de um veículo por $\mathrm{km}$ rodado - padrão de um veículo popular, modelo Gol 1.6. Este valor foi multiplicado pela distância percorrida - ida e volta - até a cidade de Cambará do Sul, pequeno município localizado a $22 \mathrm{~km}$ do PNSG, sede para quem pretende visitar o parque. Considerou-se ainda os gastos de pedágio de uma viagem ida e volta, obtidos a partir das informações de um guia rodoviário. ${ }^{15}$ Os gastos com transporte foram então ponderados pelo número declarado de ocupantes do veículo para se obter o custo per capita de transporte.

\subsection{O valor do tempo livre}

Além do próprio custo de transporte efetuado no deslocamento, o tempo gasto na viagem é outro fator com forte influência sobre a decisão do consumidor, e desconsiderar esta importante informação irá com certeza subestimar o excedente do consumidor (Hanley e Spach, 1993).

Mais que uma simples representação das horas gastas na viagem, deve-se ainda buscar uma estimativa que considere o custo de oportunidade de trabalho ou lazer da pessoa. Isso porque, a simples caracterização das horas gastas no deslocamento e estadia apresentaria dois problemas principais: i) colinearidade entre tempo e custo de viagem no modelo econométrico; ii) falsa pressuposição que todos os visitantes apresentam o mesmo custo de oportunidade.

Entretanto, o cálculo do custo de oportunidade envolve dificuldades operacionais que devem ser previstas na fase de elaboração do questionário. Enquanto alguns visitantes optam livremente entre hora de trabalho ou lazer, pois possuem uma jornada flexível de trabalho, outra grande maioria restringe suas atividades de lazer às horas vagas ou às férias anuais, já que possuem uma jornada trabalhista fixa. Se a pessoa está abrindo mão de uma hora de trabalho para visitar o patrimônio natural, a taxa salarial seria uma boa estimativa do custo de oportunidade. O tempo de viagem seria então uma ponderação do valor da hora de trabalho da pessoa. Mas, caso a visita esteja sendo feita durante as horas disponíveis de lazer, o valor do tempo de viagem deve considerar apenas o custo de oportunidade de outras atividades recreacionais disponíveis para a pessoa.

14 No caso do PNSG, os gastos com transporte representavam 54\% dos gastos totais dos visitantes.

15 As distâncias da cidade de origem à cidade de Cambará do Sul, assim como os valores dos pedágios do percurso, foram obtidos em um software de auxílio rodoviário (Guia Quatro Rodas). 
Enquanto alguns autores optam por uma estimativa padrão, como Cesario (1976) que determinou um valor de $1 / 3$ da taxa salarial para todos os visitantes, após constatar consistências em seus estudos, outros autores preferem separar os visitantes em dois grupos, com estimativas distintas do custo de viagem para cada um deles.

No caso do PNSG, os visitantes foram separados em algumas categorias ocupacionais e considerados apenas os custos de oportunidade do trabalho de algumas dessas. Excluindo-se os inativos, foram identificadas três categorias ocupacionais básicas: profissionais liberais (médicos, engenheiros, advogados, entre outros), funcionários públicos (professores e trabalhadores da administração pública) e prestadores de serviços (empregados no comércio e outros serviços). ${ }^{16}$ Apenas os custos de oportunidade dos profissionais liberais e prestadores de serviços foram considerados, já que, a rigor, os funcionários públicos apresentam uma jornada fixa de trabalho e restringem suas visitas às horas exclusivas de lazer.

Trata-se de uma estimativa conservadora, que está, de certa forma, minimizando o custo de oportunidade sem comprometer a consistência da análise. O ideal seria uma estimativa do custo de oportunidade do lazer dos funcionários públicos e inativos, que acabou não sendo feita por falta de informações mais detalhadas sobre os hábitos de lazer desses visitantes. Estimativas mais precisas para os profissionais liberais e prestadores de serviços poderiam ainda ser obtidas com questionamentos mais detalhados sobre a jornada de trabalho e a relação de trabalho dos mesmos.

\subsection{Efeito isolado da visita}

Outra questão que merece atenção especial é a diferenciação entre visitantes em férias, que tendem a permanecer mais de um dia no local de visitação, e visitantes diários, que estão apenas de passagem pelo patrimônio natural. Se o turista permanecerá mais de um dia na região, seus gastos não estarão apenas relacionados ao custo de transporte, mas também a hospedagem, alimentação e custo de oportunidade durante os dias de passeio.

No caso do PNSG, todos os gastos individuais relativos à hospedagem e alimentação foram ponderados integralmente pelo número de dias que cada visitante passou na cidade. No caso do custo de oportunidade, considerou-se o tempo gasto na viagem e os dias úteis em visita à cidade de Cambará do Sul. ${ }^{17}$

Também não se pode assumir independência entre os diversos atrativos turísticos de uma localidade, ou seja, deve-se também considerar a existência de patrimônios naturais substitutos ou complementares nas proximidades que possam estar atraindo os visitantes. Nessa condição, o visitante teria outros objetivos a cumprir na mesma viagem e apenas parte de seus gastos seria exclusivamente para visitar o patrimônio recreativo em estudo. Desconsiderar o problema de destinos múltiplos levaria, portanto, à superestimação do patrimônio natural avaliado.

Este tipo de problema é especialmente crítico no caso do PNSG, que é limítrofe ao PNAS e divide com este as ricas paisagens e o principal destino dos visitantes da região. Entre os visitantes

16 Foram entrevistados 107 (32\%) inativos, 7 (2\%) empregados no comércio e prestadores de serviços, 61 (18\%) empregados assalariados, e 160 (48\%) de profissionais liberais (médicos, advogados, dentistas, entre outros).

17 Estes dias úteis foram obtidos com base no dia de visita informado no questionário mais o número de dias da visita. Foram desconsiderados sábados e domingos. 
do PNSG, 57\% declararam ter outro destino na viagem, sendo que, entre estes, $75 \%$ com destino adicional exclusivo ao PNAS e $25 \%$ ao PNAS e outras atrações da região.

Considerar a existência de múltiplos destinos na viagem requer a elaboração de um sistema de equações simultâneas com múltiplas funções de demanda. Foi, por exemplo, o procedimento adotado por Ortiz et al. (2000) para estimar o valor de uso recreativo do Parque Nacional do Iguaçu, a partir dos custos de viagem dos múltiplos destinos (e combinações dos mesmos) dos turistas que chegam à cidade de Foz de Iguaçu. Outra proposta é apresentada por Haspel e Jonhson (1982) e consiste em dividir os custos de viagem em parcelas correspondentes aos múltiplos destinos de viagem. A parcela, ou importância, relativa de cada destino pode, por exemplo, ser estimada a partir da distância adicional percorrida ou o tempo gasto em cada destino.

A falta de informações específicas sobre gastos, tempo e distância percorrida em cada um dos múltiplos destinos dos visitantes do PNSG impediu uma estimativa mais apurada dos custos associados a cada um dos destinos. Perante estas limitações, dois procedimentos foram adotados para minimizar este tipo de viés: i) controle da função demanda pela proporção de múltiplos visitantes em cada localidade de origem; ii) desagregação do excedente total entre aqueles com único e múltiplos destinos.

Incorporou-se uma nova variável de controle na função demanda (1) para representar a proporção de visitantes com múltiplos destinos em cada localidade de origem dos visitantes do PNSG. Este controle tinha por objetivo considerar o efeito de múltiplos destinos na variação da taxa de visitação e impedir que a relação entre esta e o custo de viagem acabasse tendenciosa por falhas de especificação do modelo. ${ }^{18}$

Para considerar a parcela do benefício líquido total devida exclusivamente ao PNSG, desagregou-se a estimativa do excedente total - equação (4) - entre aqueles que visitam exclusivamente o PNSG e aqueles com múltiplos destinos na viagem. Para a parcela dos benefícios atribuída aos visitantes com múltiplos destinos, considerou-se um fator de ponderação que expressasse a importância do PNSG aos demais destinos. Em outras palavras, seja $E C_{i}$ o excedente total estimado pela equação (4) para uma dada localidade $i, p_{i}$, a proporção de visitantes desta mesma localidade com múltiplos destinos e $w_{i}$, a importância do PNSG em relação aos demais destinos da viagem. Então, pode-se afirmar que a parcela dos benefícios totais devida exclusivamente ao PNSG $\left(E C_{P N S G i}\right)$ será dada por:

$$
E C_{P_{P S G_{i}}}=\left(1-p_{i}\right) E C_{i}+p_{i} \frac{E C_{i}}{w_{i}}
$$

Embora a importância relativa do PNSG aos visitantes com múltiplos destinos, $w_{i}$, seria melhor estimada com o tempo gasto ou distância percorrida exclusivamente no PNSG, a ausência dessas informações no questionário da pesquisa obrigou a definição de um fator normativo de ponderação. Adotou-se, dessa forma, um peso de $50 \%$ para o PNSG, já que parcela majoritária dos visitantes com múltiplos destinos divide suas atividades de lazer basicamente entre o PNSG e o PNAS.

18 Detalhes sobre o efeito desta variável na demanda por visitação serão apresentados na subseção 4.5. 


\subsection{Escolha da forma funcional}

O valor agregado dos gastos observados com transporte, alimentação, hospedagem e custo de oportunidade, corresponde aos gastos efetivos de visitação ao PNSG. Ajustando estes valores à taxa observada de visitação, é possível estimar a função demanda pelo patrimônio natural e, assim, obter o excedente do consumidor, a estimativa do benefício econômico líquido do patrimônio para a população.

Os gastos efetivos médios observados no PNSG foram de R $\$ 459$ com transporte, $\mathrm{R} \$ 77$ com alimentação, $R$ \$ 131 com hospedagem e $R$ \$ 186 de custo de oportunidade, totalizando um custo individual médio de $\mathrm{R} \$ 854$ reais. Considerando as 29 mil visitas anuais esperadas, ${ }^{19}$ há um gasto efetivo anual médio da ordem de R $\$ 25$ milhões proporcionado pelo PNSG.

Para ajustar a função demanda (1) pelo PNSG a partir dos gastos efetivos, pode ser utilizada uma variedade de formas funcionais, estando as mais freqüentes apresentadas na Tabela 2. A escolha da forma funcional mais apropriada será de fundamental importância para o resultado final, pois alterações mínimas nos parâmetros podem representar mudanças significativas no excedente total.

Como não há consenso teórico quanto à forma mais apropriada, a escolha deve basear-se, preferivelmente, no melhor ajuste econométrico. Deve-se, portanto, considerar tanto a representatividade da variável dependente, quanto a verificação de alguns pressupostos básicos do modelo de regressão, como a homocedasticia e normalidade dos resíduos. ${ }^{20}$

Embora o coeficiente de determinação $\left(\mathrm{R}^{2}\right)$ seja o procedimento mais freqüente de análise da qualidade do ajuste, este refere-se a uma medida da variabilidade do regressando, explicada pelo ajuste econométrico, e pode apenas ser comparado entre modelos com o mesmo regressando. Ou seja, é comparável apenas entre os modelos linear e lin-log, e entre os modelos log-lin e log-log.

\section{Tabela 2 - Algumas formas funcionais mais comuns para a função demanda}

\section{Forma Funcional Características dos parâmetros}

\begin{tabular}{ll}
\hline $\begin{array}{l}\text { Linear: } \\
V=\beta_{0}+\beta_{1} C V+\sum_{j} \beta_{j} X+e\end{array}$ & $\begin{array}{l}\text { O parâmetro } \beta_{1} \text { estima a variação absoluta na taxa de visitação } V, \text { dado um } \\
\text { aumento unitário absoluto no custo de viagem } C V .\end{array}$ \\
\hline $\begin{array}{ll}\text { Lin-log: } \\
V=\beta_{0}+\beta_{1} \ln (C V)+\sum_{j} \beta_{j} X+e\end{array}$ & $\begin{array}{l}\text { O parâmetro } \beta_{1} \text { estima a variação absoluta na taxa de visitação } V \text {, dado um } \\
\text { aumento relativo (\%) no custo de viagem } C V .\end{array}$ \\
\hline $\log -\operatorname{lin}:$ & $\begin{array}{l}\text { O parâmetro } \beta_{1} \text { estima a variação relativa (\%) na taxa de visitação } V, \text { dado um } \\
\text { aumento unitário absoluto no custo de viagem } C V .\end{array}$ \\
\hline $\ln (V)=\beta_{0}+\beta_{1} C V+\sum_{j} \beta_{j} X+e$ & $\begin{array}{l}\text { O parâmetro } \beta_{1} \text { é uma estimativa constante da elasticidade preço da visita, ou seja, } \\
\text { qual a variação relativa (\%) na taxa de visitação } \mathrm{V} \text { dada por uma variação relativa } \\
\text { (\%) no custo de viagem } C V .\end{array}$ \\
\hline $\ln (V)=\beta_{0}+\beta_{1} \ln (C V)+\sum_{j} \beta_{j} X+e$
\end{tabular}

19 A estimativa das visitas anuais foi feita projetando uma linha de tendência a partir do histórico de visitas fornecido pela direção do parque.

20 Caso os questionários sejam coletados durante longos períodos de tempo, sugere-se ainda que seja verificada a presença de autocorrelação serial nos resíduos. 
Neste sentido, a análise dos resíduos torna-se essencial na escolha da melhor forma funcional. Esses devem estar normalmente distribuídos em torno da média nula para que as estatísticas de teste do modelo sejam válidas, e devem apresentar variância homogênea (homocedasticia) para que os coeficientes estimados sejam confiáveis. ${ }^{21}$ Para testar os pressupostos de normalidade e homocedasticia dos resíduos, este trabalho optou pelos testes estatísticos de Jarque-Bera e White. A estatística Jarque-Bera $(J B)$ realiza um teste assintótico da hipótese nula de normalidade baseada nas medidas de assimetria e curtose dos resíduos. ${ }^{22}$ Já o teste de White $\left(n R^{2}\right)$ verifica a veracidade da hipótese nula de homocedasticia a partir da relação linear entre os resíduos obtidos no ajuste e as variáveis independentes do modelo. ${ }^{23}$

A Tabela 3 apresenta o resumo dos resultados para as quatro principais formas funcionais da função demanda por visitas do PNSG. A variável $V$ representa o número anual visitas para cada grupo de mil habitantes da localidade $i$, e $C V$ é custo médio de viagem dos visitantes da localidade $i$, obtido pela soma dos gastos médios com transporte, hospedagem, alimentação e custo de oportunidade. Para melhorar a representatividade do ajuste e controlar o efeito de outras variáveis na demanda do PNSG, foram ainda incorporadas as variáveis AnosEst ${ }_{i}$ (média dos anos de escolaridade daqueles com 15 anos ou mais de idade na localidade $i$ ), Múltiplo (proporção de visitantes da localidade $i$ com múltiplos destinos) e uma variável binária RS (que assume o valor 1 quando a localidade $i$ pertencer ao Estado do Rio Grande do Sul e 0, caso contrário) para indicar a relevância do Estado sede do parque nacional na demanda por visitação. ${ }^{24}$

Embora todos os ajustes apresentem estatísticas $F$ significativas, há diferenças relevantes na qualidade dos ajustes. Em ambas as formas lineares do regressando (linear e lin-log), os resíduos não estão normalmente distribuídos tampouco apresentam variância constante. As estatísticas $J B$ e $n R^{2}$ apresentadas nos ajustes (a) e (b) rejeitam as hipóteses nulas de normalidade e homocedasticia dos resíduos com significâncias fortíssimas $(\mathrm{p}<0,001)$.

Aplicando-se o logaritmo natural ao regressando $V$, os pressupostos de normalidade e homecedasticia dos resíduos passam a ser satisfeitos. As estatísticas $J B$ e $n R^{2}$ apresentaram valores insignificantes, de forma que as hipóteses de normalidade e homocedasticia dos resíduos não são rejeitadas. Como ambos ajustes apresentam o mesmo regressando $(\ln V)$, os coeficientes de determinação são também comparáveis e sugerem que os modelos log-lin e log-log são praticamente semelhantes. Optou-se, entretanto, pelo ajuste log-log por este ainda permitir uma associação direta com elasticidade-preço da visita.

21 Para maiores detalhes sobre os pressupostos de um modelo de regressão linear múltipla ver Gujarati (1995).

22 Sob a hipótese nula de normalidade dos resíduos, a estatística $J B$ definida por $J B=n\left[\frac{S^{2}}{6}+\frac{(K-3)^{2}}{24}\right]$ seguirá uma distribuição $\chi^{2}$ com 2 graus de liberdade, onde $S$ é o coeficiente de assimetria dos resíduos, $K$, o coeficiente de curtose, e $n$, o tamanho da amostra. Para maiores detalhes, ver Jarque e Bera (1987).

23 Para testar a homocedasticia dos resíduos, o teste assintótico de White realiza um ajuste auxiliar utilizando como variável dependente o quadrado dos resíduos obtidos pelo ajuste original e, como variáveis independentes, as variáveis explicativas da forma funcional original, seus valores elevados ao quadrado e os produtos cruzados dos regressores. Sob a hipótese nula de homocedasticia dos resíduos, a estatística $n R^{2}$ (onde $n$ é o número de observações e $R^{2}$ o coeficiente de determinação do ajuste auxiliar) terá uma distribuição $\chi^{2} \operatorname{com} g l$ graus de liberdade, onde $g l$ é o número de varíaveis independentes do ajuste auxiliar. Para maiores detalhes, ver White (1980).

24 Foram ainda testadas outras variáveis, tais como renda per capita e idade média da localidade de origem, mas estas mostraram-se insignificantes em todos os ajustes. 
Tabela 3 - Formas funcionais ajustadas para a demanda por visitas ao PNSG

a) Linear: $V=\beta_{0}+\beta_{1} C V+\beta_{2}$ AnosEst $+\beta_{3}$ Multiplo $+\beta_{4} R S+e$

\begin{tabular}{lcccccc}
\hline & Coef & $t$ & $p$ & & Coef & $p$ \\
\hline Interc & 0,7394 & 1,58 & 0,117 & $\mathrm{R}^{2}$ & 0,597 & \\
CV & $-0,0004$ & $-1,50$ & 0,138 & $\mathrm{~F}$ & 33,4 & $* * *$ \\
AnosEst & 2077,2122 & 9,81 & ${ }^{* * *}$ & $\mathrm{JB}$ & 925,7 & $* * *$ \\
Multiplo & $-0,1503$ & $-0,38$ & 0,7021 & $\mathrm{nR}^{2}$ & 75,2 & $* * *$ \\
RS & 0,2711 & 0,66 & 0,5092 & & & \\
\hline
\end{tabular}

b) Lin-Log: $V=\beta_{0}+\beta_{1} \ln (\mathrm{CV})+\beta_{2}$ AnosEst $+\beta_{3}$ Multiplo $+\beta_{4} R S+e$

\begin{tabular}{lcccccc}
\hline & Coef & $t$ & $p$ & & Coef & $p$ \\
Interc & 3,0550 & 1,45 & 0,151 & $\mathrm{R}^{2}$ & 0,596 & \\
In (CV) & $-0,4054$ & $-1,36$ & 0,176 & $\mathrm{~F}$ & 38,1 & $* * *$ \\
AnosEst & 2053,9322 & 9,55 & ${ }^{* * *}$ & $\mathrm{JB}$ & 977,3 & $* * *$ \\
Multiplo & $-0,1380$ & $-0,35$ & 0,726 & $\mathrm{nR}^{2}$ & 73,5 & $* * *$ \\
RS & 0,2368 & 0,55 & 0,583 & & & \\
\hline
\end{tabular}

c) Log-Lin: $\ln (V)=\beta_{0}+\beta_{1} C V+\beta_{2}$ AnosEst $+\beta_{3}$ Multiplo $+\beta_{4} R S+e$

\begin{tabular}{lcccccc}
\hline & Coef & $t$ & $p$ & & Coef & $p$ \\
\hline Interc & $-0,6779$ & $-3,01$ & 0,003 & $\mathrm{R}^{2}$ & 0,622 & \\
CV & $-0,0004$ & $-2,85$ & 0,005 & $\mathrm{~F}$ & 37,1 & $* * *$ \\
AnosEst & 725,1380 & 7,12 & $* * *$ & $\mathrm{JB}$ & 1,6 & 0,457 \\
Multiplo & 0,3228 & 1,71 & 0,090 & $\mathrm{nR}^{2}$ & 14,1 & 0,369 \\
RS & 0,6969 & 3,54 & $* * *$ & & & \\
\hline
\end{tabular}

d) Log-Log: $\ln (V)=\beta_{0}+\beta_{1} \ln (C V)+\beta_{2}$ AnosEst $+\beta_{3}$ Multiplo $+\beta_{4} R S+e$

\begin{tabular}{lcccccc}
\hline & Coef & $t$ & $p$ & & Coef & $p$ \\
\hline Interc & 1,0068 & 0,97 & 0,333 & $\mathrm{R}^{2}$ & 0,608 & \\
$\ln (\mathrm{CV})$ & $-0,3092$ & $-2,13$ & 0,036 & $\mathrm{~F}$ & 34,9 & $* * *$ \\
AnosEst & 712,6527 & 6,77 & $* * *$ & $\mathrm{JB}$ & 1,8 & 0,400 \\
Multiplo & 0,3412 & 1,78 & 0,079 & $\mathrm{nR}^{2}$ & 14,0 & 0,374 \\
RS & 0,7109 & 3,38 & 0,001 & & & \\
\hline
\end{tabular}

**** Significância a $0,1 \%$.

De acordo com os coeficientes do modelo log-log, o parque apresenta uma demanda relativamente inelástica ao custo de viagem; um acréscimo de $1 \%$ no custo da viagem implicaria uma redução de apenas $0,3 \%$ na taxa de visitação. Este resultado sugere a relevância dos atrativos para seus visitantes, turistas ecológicos que usualmente apresentam aceitável padrão social e dificilmente encontrariam um substituto semelhante de lazer nas diversas localidades do País. A expressiva 
relação positiva entre escolaridade média da localidade de origem e a taxa de visitação reforça esta análise e sugere a associação do turismo ecológico às populações mais instruídas do País.

Como discutido nos tópicos anteriores, a possibilidade de visitar outros destinos na viagem contribuiu positivamente para a disposição dos visitantes, que usualmente enfrentam longas distâncias para chegar ao PNSG. E, independente dos demais fatores, nos municípios do Estado do Rio Grande do Sul, a taxa de visitação é ainda $104 \%$ superior a dos demais, ${ }^{25}$ o que pode estar associado à maior divulgação pelas agências de turismo e conhecimento do parque por parte dos habitantes desse Estado.

\subsection{Cálculo do excedente do consumidor}

Após estimar a função demanda por visitas (1), deve-se proceder ao cálculo do excedente do consumidor, uma estimativa do benefício líquido direto dos serviços ambientais prestados pelo patrimônio à população. Segundo a expressão (4), o excedente de uma dada localidade $i$ (supondo uma função demanda agregada) seria obtido pelo cálculo da área abaixo da função demanda, delimitada entre o custo de viagem efetivamente praticado pelos visitantes da localidade $i\left(c v_{i}\right)$ e o ponto onde a demanda seja estrangulada em virtude dos preços excessivamente altos do custo de viagem $(c v \rightarrow \infty)$.

Entretanto, se for, por exemplo, assumida uma curva exponencial como representação da função demanda, esta pressuposição levaria a estimativas razoavelmente elevadas, já que o modelo assumiria uma redução exponencial da taxa de visitação em relação a pequenas variações no custo de viagem. A solução freqüentemente adotada é a adoção de um custo de viagem máximo (ou demanda de visitação mínima), a partir do qual a demanda seria assumida como nula em virtude dos gastos relativamente elevados de viagem. Dessa forma, o cálculo do excedente $E C_{i}$ de uma localidade $i$ seria, na prática, dado pela expressão:

$$
E C_{i}=\int_{C V i}^{C V \max } f\left(C V_{i}, S E_{i}, S B_{i}\right) d C V
$$

onde $C V_{i}$ é o custo efetivo de viagem para os visitantes da localidade $i, \mathrm{CV}_{\max }$ é o valor máximo onde a demanda é reprimida pelo alto custo de viagem, $S E_{i}$ representa as características socioeconômicas da localidade $i$, e $S B_{i}$ é o custo de viagem do substituto mais próximo. Agregando-se os excedentes de todas as localidades chega-se à estimativa do excedente total dos serviços ambientais prestados pelo patrimônio natural à população.

A partir da forma funcional log-log adotada para representar a função demanda por visitas do PNSG (Tabela 3d), a estimativa dos benefícios de uso direto do parque, para cada localidade de origem $i$, será, portanto, dada pelo desenvolvimento:

$$
E C_{i}=\int_{C V i}^{C V \max } e^{\hat{\beta}_{0}+\hat{\beta}_{1} \ln \left(C V_{i}\right)+\hat{\beta}_{2} \text { AnosEst } t_{i}+\hat{\beta}_{3} \text { Multiplo }_{i}+\hat{\beta}_{4} R S_{i}} d C V
$$

25 A variação relativa para uma variável dicotômica em equações semilogarítmicas é dada por $e^{\beta}-1$, onde $\beta$ é o coeficiente da variável dicotômica (Halvorsen e Palmquist, 1980). 


$$
E C_{i}=\left(\frac{C V_{\max }^{1+\hat{\beta}_{1}}-C V_{i}^{1+\hat{\beta}_{1}}}{1+\hat{\beta}_{1}}\right) e^{\hat{\beta}_{0}+\hat{\beta}_{2} \text { AnosEst }_{i}+\hat{\beta}_{3} \text { Multiplo }_{i}+\hat{\beta}_{4} R S_{i}}
$$

Considerou-se como custo máximo de viagem, $C V_{\max }$, o valor referente ao município de Recife, onde a taxa de visitação era praticamente nula (0,034 visitas para cada grupo de 1.000 habitantes), em virtude do gasto de viagem relativamente elevado ( $\mathrm{R} \$ 3.324$ por visitante). ${ }^{26}$

O excedente estimado pela expressão (9) refere-se a estimativas anuais para cada grupo de mil habitantes de uma localidade $i$, dada a relação definida pela variável dependente na função da função demanda (visitas/1.000 hab). Expandindo os valores à população total de cada localidade ${ }^{27}$ e agregando os valores das 95 localidades da amostra, chega-se a uma estimativa anual de benefícios líquidos equivalente a $\mathrm{R} \$$ 46.688.246. Como apresentado anteriormente, este valor desconsidera o problema de múltiplos destinos dos visitantes. Considerando apenas a parcela devida ao PNSG - expressão (6) - chega-se à estimativa dos benefícios exclusivos do PNSG equivalente a R\$ 33.443.674.

\subsection{Confiabilidade das estimativas}

A precisão das estimativas é de fundamental importância na confiabilidade do resultado da valoração, já que variações mínimas nos coeficientes do modelo tendem a gerar mudanças significativas na estimativa do benefício líquido total. Para garantir maior confiabilidade à estimativa do $\mathrm{MCV}$, o planejamento da pesquisa deve privilegiar não somente a escolha da forma funcional mais apropriada, mas também o processo de seleção da amostra e ajustamento dos dados.

Para simular o impacto de pequenas variações dos coeficientes na estimativa do excedente agregado do PNSG e discorrer sobre a forma apropriada de planejamento da pesquisa, será feito um novo ajuste econométrico, eliminando apenas um dos questionários da amostra. O objetivo é mostrar como pequenos desvios da amostra podem desencadear efeitos significativos na estimativa do benefício líquido total.

O município de São Joaquim da Barra possuía, em 2004, uma população estimada de 44.304. ${ }^{28}$ Seu único visitante entrevistado no PNSG durante o período de coleta dos dados representava, em valores expandidos, uma população de 109 habitantes, o que equivale afirmar que a taxa de visitação anual esperada para esta localidade era de 2,46 visitas para cada grupo de 1.000 habitantes. Já o valor previsto pela forma funcional log-log para a taxa de visitação deste município era de 0,76 visitas para cada grupo de 1.000 habitantes, apresentando, portanto, um desvio de 1,70 unidades em relação ao valor observado. Mesmo não se tratando do valor observado mais extremo em relação

26 Considera-se, desta maneira, remota a probabilidade de uma visita dado um custo individual médio superior a 2.705 reais.

27 Valores estimados a partir dos dados do Censo Demográfico 2000 e das taxas estimadas de crescimento municipal fornecidas pelo IBGE.

28 Projeção feita pelo autor com base na população observado do Censo Demográfico 2000 e na taxa de crescimento populacional do Estado de São Paulo fornecida pelo IBGE. 
aos previstos pelo modelo, ${ }^{29}$ a exclusão desse questionário foi suficiente para ilustrar o impacto de pequenas variações dos coeficientes na estimativa do excedente agregado.

Eliminando, portanto, o questionário correspondente ao município de São Joaquim da Barra, foi obtido um novo ajuste para a função demanda, com as informações relativas aos 94 municípios restantes e as devidas correções nos fatores de expansão populacional. Por se tratar de um valor observado relativamente extremo ao esperado, a exclusão deste questionário tornou o ajuste log-log ainda mais significativo, como mostram os resultados da Tabela 4.

Tabela 4 - Ajuste para a demanda por visitas ao PNSG $^{(1)}$

Log-Log: $\ln (V)=\beta_{0}+\beta_{1} \ln (C V)+\beta_{2}$ AnosEst $+\beta_{3}$ Multiplo $+\beta_{4} R S+e$

\begin{tabular}{lcccccc}
\hline & Coef & $t$ & $p$ & & Coef & $p$ \\
\hline Interc & 1,245 & 1,20 & 0,234 & $\mathrm{R}^{2}$ & 0,615 & \\
$\ln (\mathrm{CV})$ & $-0,343$ & $-2,34$ & 0,021 & $\mathrm{~F}$ & 35,5 & $* * *$ \\
AnosEst & 699,610 & 6,67 & $* * *$ & $\mathrm{JB}$ & 1,8 & 0,408 \\
Múltiplo & 0,304 & 1,58 & 0,117 & $\mathrm{nR}^{2}$ & 13,5 & 0,411 \\
RS & 0,716 & 3,43 & 0,001 & & & \\
\hline
\end{tabular}

**** Significância a $0,1 \%$.

(1) Excluindo município de São Joaquim da Barra.

Substituindo os coeficientes da expressão (9) pelos valores da Tabela 4, obteve-se uma nova estimativa dos benefícios líquidos para cada grupo de 1.000 habitantes da localidade de origem $i$. Agregando os excedentes de todos as localidades da amostra, chegou-se à nova estimativa anual de benefícios líquidos totais (desconsiderando o problema dos múltiplos destinos), equivalente a $\mathrm{R} \$$ 44.898.804. Considerando apenas a parcela devida ao PNSG, expressão (6), estimou-se o novo benefício líquido exclusivo do PNSG em R\$32.274.446. Em outras palavras, a exclusão de um único entrevistado foi suficiente para reduzir a estimativa dos benefícios do PNSG em mais de 1 milhão de reais anuais, uma estimativa 3,5\% inferior à original.

Este resultado permite discutir a relevância de duas fases fundamentais no processo de análise estatística: i) o planejamento amostral para garantir a representatividade da população, e ii) o tratamento dos dados para dar mais qualidade ao ajuste econométrico.

Se os critérios adequados de seleção amostral não forem rigorosamente adotados, pequenos desvios nos valores observados podem tornar os resultados finais bastante incorretos. O essencial é garantir que a amostra seja representativa da população, ou seja, que, desconsiderando pequenas discrepâncias inerentes à aleatoriedade sempre presente, em maior ou menor grau, no processo de amostragem, essa deve possuir as mesmas características básicas da população. Para isso, recomenda-se o máximo respeito aos critérios de aleatoriedade na seleção da amostra, com o emprego, se possível, de técnicas de estratificação que garantam a representatividade dos distintos grupos da

29 O município de Cambará do Sul apresentava o maior desvio em relação ao ajuste, com uma taxa de visitação observada de 2,2 e uma taxa esperada de visitação esperada pelo ajuste de 42,3 visitas/1.000 hab. 
população, das distintas regiões de procedência dos visitantes e considere o caráter sazonal das visitas.

Da mesma forma, o tratamento dos dados deve cumprir com o papel de aperfeiçoar o ajuste, sem comprometer a representatividade da população. Valores extremos tendem a afetar particularmente o resultado final, e devem ser analisados com muita cautela. Estes costumam estar associados a pequenas localidades, que geram altas taxas de visitação, ou visitantes de locais muito distantes, que geram altos custos de viagem. Uma sugestão é que estes valores sejam agregados às localidades próximas, representando micro ou mesorregiões geográficas, como forma de atenuar o efeito extremo das estimativas observadas. Em geral, a adoção de localidades mais agregadas tende a reduzir a flutuação aleatória e reforçar as relações estatísticas. Por outro lado, localidades mais desagregadas produzem maior homogeneidade interna e permitem maior flexibilidade na análise.

O ideal seria, entretanto, a seleção de amostras relativamente grandes, que minimizariam o efeito de valores extremos na estimativa dos coeficientes. O problema é que essas costumam estar seriamente comprometidas pela disponibilidade de tempo e dinheiro para realização da pesquisa.

\section{ANÁlISE DOS RESULTADOS E CONSIDERAÇÕES FINAIS}

A valoração econômica é uma ferramenta essencial para avaliação de projetos ambientais e para tomada de decisões, por exemplo, em processos judiciais de indenização por danos causados ao ambiente ou desapropriação de propriedades privadas. Como afirma Pearce (1993), não se trata de transformar um bem ambiental em um produto de mercado, mas sim mensurar as preferências dos indivíduos sobre alterações em seu ambiente. O problema é que a falta de critério na realização da pesquisa pode, muitas vezes, ser responsável pelo comportamento oportunista dos agentes, exigindo, acima de tudo, estudos criteriosos sobre a validade e confiabilidade da estimativa econômica no processo de tomada de decisão.

Para verificar a validade e confiabilidade de uma aplicação do método de custo de viagem, este trabalho analisou o caso do Parque Nacional da Serra Geral. A pesquisa destinava-se a subsidiar a justiça em um processo de indenização aos proprietários desapropriados. A escolha do método de custo de viagem baseou-se na pertinência do método ao caso em estudo, um parque de visitação pública, ao mesmo tempo em que se buscou considerar uma maior gama de atributos ambientais em relação a outros métodos indiretos e dar credibilidade às estimativas econômicas, associando-as a gastos efetivamente praticados pela população.

A revisão dos pressupostos teóricos da metodologia reuniu argumentos para analisar o conteúdo da estimativa, ou seja, se essa refletia a dimensão analítica do problema e era factível à proposta judicial. Segundo a teoria econômica do excedente do consumidor, a estimativa obtida pelo método de custo de viagem refere-se ao benefício líquido do parque à população, ou seja, quanto a mais do que é efetivamente gasto a população estaria disposta a pagar para visitar o parque. Trata-se, portanto, apenas de uma estimativa para os valores de uso dos atributos ambientais existentes no parque, obtida a partir do comportamento observado na população visitante. 
Procurou-se ainda seguir as principais recomendações da literatura durante a execução da pesquisa. Em algumas situações, como no cálculo do custo de oportunidade e dos custos de transporte, adotou-se soluções conservadoras, ou seja, que minimizassem a probabilidade de supervaloração do recurso sem comprometer a confiabilidade da estimativa. Esforços esses realizados para não colocar em dúvida a credibilidade do valor econômico durante o processo de avaliação judicial.

Visitantes com múltiplos destinos exigem ainda planejamento específico da pesquisa para a elaboração de múltiplas funções de demanda ou a adoção de um fator de ponderação que expresse a importância do patrimônio avaliado em relação aos demais. A ausência de informações específicas na pesquisa aplicada ao PNSG exigiu, entretanto, a adoção de um fator normativo de ponderação dos benefícios líquidos totais dos visitantes com múltiplos destinos. Desconsiderar este problema levaria à superestimação do patrimônio natural que, no caso do PNSG, chegaria a $40 \%$ do valor estimado.

Simulando o efeito de possíveis variações da amostra sobre o resultado final da valoração, foi ainda possível analisar a confiabilidade das estimativas. Embora a exclusão de valores extremos seja procedimento freqüente na fase de tratamento dos dados, verificou-se que pequenas alterações dos valores observados podem ser responsáveis por mudanças significativas no resultado final. Tais resultados sugerem, acima de tudo, um acompanhamento criterioso durante toda a execução desse tipo de pesquisa, do planejamento amostral ao tratamento dos dados.

De maneira geral, conclui-se que a estimativa do método de custo de viagem, com respaldo na teoria econômica do excedente do consumidor, pode ser considerada uma medida válida dos benefícios efetivos do parque à população. Entretanto, a forte sensibilidade constatada nas estimativas em relação a pequenas variações dos coeficientes recomenda cuidados especiais na interpretação dos resultados. Embora a pesquisa forneça uma base válida de referência para os reais benefícios do patrimônio à população, um critério alternativo de avaliação econômica deve ser sempre recomendado, especialmente em processos de indenização judicial.

No caso do PNSG, a diferença entre a estimativa do MCV e a do preço das propriedades, baseado na produtividade média da pecuária, gerou diferenças significativas. Considerando, por exemplo, um horizonte de 25 anos, o benefício líquido exclusivo do PNSG equivaleria a um valor presente $^{30}$ da ordem de $\mathrm{R} \$ 283$ milhões, ou $\mathrm{R} \$ 16 \mathrm{mil} / \mathrm{ha}$, valor 11 vezes superior ao preço de mercado das propriedades. Embora a decisão sobre qual das estimativas melhor reflete o real valor adas propriedades desapropriadas esteja além dos objetivos deste trabalho, espera-se ter contribuído para futuras aplicações do gênero, na medida em que se apresentou os princípios teóricos, metodológicos e principais limitações do MCV.

\section{REFERÊNCIAS}

BOUMANS, Roelof et al. Modeling the dynamics of integrated earth system and the value of global ecosystem services using the GUMBO model. Ecological Economics, v. 41, p. 529-560, 2002.

30 Valor presente líquido considerando uma taxa de retorno de $12 \%$ ao ano. 
BROMLEY, Daniel W. Handbook of Environment Economics. Cambridge: Blackwell Publisher, 1995. 705 p.

CARMINES, Edward G.; ZELLER, Richard A. Reliability and validity assessments. Beverley Hills: Sage, 1979.

CESARIO, Frank J. Value of Time in Recreation Benefit Studies. Land Economics, Madison, v. 52, p. 32-41, 1976.

COCHRAN, Willian G. Sampling techniques. New York: John Wiley, 1953.

DE CARLO, Sandra. Sistema integrado de contas econômico-ambientais - SICEA. Rio de Janeiro: IBGE, 2000. (Texto para Discussão, n. 1).

GUJARATI, D. N. Basic econometrics. Nova Iorque: McGraw-Hill, 3. ed., 1995.

HANLEY, Nick; SPACH, Clive L. Cost-benefit analysis and the environment. Hants: Edward Elgar, 1993.

HALVORSEN, Robert; PALMIQUIST, Raymond. The interpretation of dummy variables in semilogarithmic equations. The American Economic Review, Pittsburg, v. 70, n. 3, p. 474-475, jun. 1980.

HASPEL, Abraham E.; JOHNSON, F. Reed. Multiple destination trip bias in recreation benefit estimation. Land Economics, Madison, v. 58, p. 364-372, 1982.

JARQUE, C. M.; BERA, A. K. A test for normality of observations and regression residual. International Statistical Review, v. 55, n. 2, p. 163-172, 1987.

MAIA, A. Gori; ROMEIRO, Ademar R.; REYDON, Bastiaan P. Valoração de recursos ambientais: metodologias e recomendações. Campinas: IE/UNICAMP, n. 116, 2004. (Texto para Discussão, n. 116).

ORTIZ, Ramon A.; SEROA DA MOTTA, Ronaldo; FERRAZ, Claudio. A estimação do valor ambiental do Parque Nacional do Iguaçu através do método de custo de viagem. Pequisa e Planejamento Econômico, v. 30, n. 3, p. 355-382, dez. 2000.

PEARCE, David W. Economic values and the natural world. Massachusetts: MIT, 1993.

ROMEIRO, Ademar R. O papel dos indicadores de sustentabilidade e da contabilidade ambiental. In: ROMEIRO, A .R. (Org). Avaliação e Contabilização de Impactos Ambientais. Campinas: Editora da Unicamp, São Paulo: Imprensa Oficial do Estado de São Paulo, 2004.

SMITH, V. Kerry; KAORU, Yoshiaki. Signals or noise? Explaining the variation in recreation benefit estimates. American Journal of Agricultural Economics, v. 72, n. 2, p. 419-433, 1990.

WILLIS, K.; GARROD, G. An individual travel cost method of evaluating forest recreation. Journal of Agricultural Economics. v. 42, n. 1, p. 33-42, 1989.

WHITE, Halbert. Heterocedasticity consistent covariance matrix estimator and a direct test of heterocedasticity. Econometrica, v. 48, p. 817-818, 1980. 